was used were noticeably drier. The quantity of intravenous sedative used does not appear to be significant, as those patients that aspirated had not had unusually high doses.

When we reviewed the radiographs of those patients who had aspirated, five out of $16(31.3 \%)$ had evidence of aspiration into the right lower zone. It would be unlikely that aspiration would occur into this site while lying on the left side, and we therefore concluded that the patients had aspirated when sitting upright after the examination. Aspiration presumably occurred some 40 minutes after initial sedation. At this time the action of the sedatives is diminished but local anaesthesia is still prominent. Efficient oropharyngeal anaesthesia, however, is an essential prerequisite of gastrointestinal fibre-endoscopic examination. Consequently we no longer allow patients to sit up after examination. They are instructed to stay horizontal until pharyngeal anaesthesia is no longer present.

Another factor contributing to the risk of aspiration is the mechanical interference with glottic closure and swallowing caused by the presence of the fibrescope. This and the effect of local anaesthesia are unavoidable.

We do not think that the nature of the intravenous sedative used is of prime importance as has been suggested elsewhere (Taylor et al., 1972) but is due to the unavoidable features inherent in this particular type of examination. We wish to draw attention to the fact that aspiration occurs more commonly than may have been suspected, although rarely followed by serious complications. None occurred in the present series. We therefore suggest that clinicians referring patients for endoscopy should be aware of the risk of pulmonary aspiration complicating the investigation.

We wish to thank Sister M. M. Symons and Mrs. B. Jewell for their help with the examinations, and Miss F. Hocking for typing the manuscript.

\section{References}

Dundee, J. W., and Haslett, W. H. K. (1970). British fournal of Anaesthesia, 42, 217.

Healey, T. E. J and Vickers, M.D. (1971). Proceedings of the Royal Society of Medicine, 64, 85.

Metreweli, C., and Prout, B. J. (1972). In press.

Taylor, P. A., Cotton, P. B., Towey, R. M., and Gent, A. E. (1972). British Medical Fournal, 1, 666.

\title{
Rubella Vaccination and Termination of Pregnancy
}

\author{
HÉLENE J. MAIR, ALAN R. BUCHAN
}

British Medical fournal, 1972, 4, 271-273

\section{Summary}

Six terminations of pregnancy have been carried out in Leicestershire since February 1970 because of rubella vaccine administered inadvertently during early unrecognized pregnancy. Any woman of child bearing age shown by serological tests to be susceptible to rubella should be offered vaccination, preceded and followed by adequate contraception.

\section{Introduction}

Circular 17/72 from the Department of Health and Social Security (1972) advises against routine rubella vaccination of women of childbearing age but recommends immunization for women in this age group who request protection, for women in the postpartum period, and for women at special risk of acquiring or transmitting rubella, provided in all cases that they are seronegative and are fully aware of the need to avoid pregnancy for at least two months after receiving the vaccine.

Public Health Laboratory, Leicester

HÉLÈNE J. MAIR, M.D., M.R.C.PATH., Consultant Virologist

County Health Department, Leicestershire

ALAN R. BUCHAN, M.D., D.P.H., County Medical Officer
Vaccination programmes are still in the early stages, but already experience in Leicestershire indicates that the safe administration of rubella vaccine is not as simple as might appear at first sight.

\section{Preliminary Findings}

Termination of pregnancy after rubella vaccination was considered necessary on six occasions in which the Public Health Laboratory in Leicester was involved between February 1970 and May 1972 (see Table). Three of the terminations (Cases 4, 5, and 6) were performed within 14 weeks in 1972 . With the exception of the pregnancy of a 16-year-old unmarried girl (Case 2), all were "wanted" babies. Cases 1 and 3 were known to be seronegative before vaccination, and both women had been advised not to become pregnant for at least eight weeks. One started menstruation the day after vaccination but conceived within the next 14 days. Arrangements were made for termination at 11 weeks but spontaneous abortion occurred a week earlier. The products of conception did not contain rubella virus (MacDonald et al., 1971).

Rubella vaccine was given to the remaining four women without previous estimation of their immune state. At least one woman is known not to have received any warning of the risks of pregnancy when immunized by a relief surgery nurse. In the case of the unmarried girl her doctor judged the risk of pregnancy to be negligible and advice therefore unnecessary. In four

Details of Patients inoculated with Rubella Vaccine during Pregnancy

\begin{tabular}{|c|c|c|c|c|c|c|}
\hline Case No. & Age & $\begin{array}{c}\text { Prevaccination } \\
\text { Haemagglutination } \\
\text { Inhibition Test }\end{array}$ & Last Menstrual Period & Date of Vaccination & $\begin{array}{c}\text { Postvaccination } \\
\text { Haemagglutination } \\
\text { Inhibition Test }\end{array}$ & Termination \\
\hline $\begin{array}{l}1 \\
2 \\
3\end{array}$ & $\begin{array}{l}23 \\
16 \\
20\end{array}$ & \multirow[t]{2}{*}{$\begin{array}{c}5 \text { December } 1969,<8 \\
23 \text { March } 1971,<8 \\
6 \text { April } 1971,<8\end{array}$} & $\begin{array}{l}16 \text { December } 1969 \\
12 \text { October } 1970 \\
15 \text { April } 1971\end{array}$ & $\begin{array}{c}15 \text { December } 1969 \\
2 \text { November } 1970 \\
22 \text { April } 1971\end{array}$ & $\begin{array}{l}27 \text { January } 1970,+80 \\
11 \text { March } 1971,+128 \\
26 \text { June } 1971,+256\end{array}$ & $\begin{array}{c}28 \text { February } 1970 \\
11 \text { March } 1971 \\
7 \text { July } 1971\end{array}$ \\
\hline $\begin{array}{l}4 \\
5 \\
6\end{array}$ & $\begin{array}{l}25 \\
25 \\
27\end{array}$ & & $\begin{array}{l}13 \text { November } 1971 \\
11 \text { February } 1972 \\
18 \text { February } 1972\end{array}$ & $\begin{array}{c}19 \text { November } 1971 \\
19 \text { February } 1972 \\
8 \text { March } 1972\end{array}$ & $\begin{array}{c}28 \text { January } 1972,+32 \\
28 \text { April 1972, }+64\end{array}$ & $\begin{array}{l}7 \text { February } 1972 \\
26 \text { April } 1972 \\
11 \text { May } 1972\end{array}$ \\
\hline
\end{tabular}


instances vaccination was carried out within a week of the first day of the last menstrual period. After termination of pregnancy the products of conception from each case were examined virologically with negative results.

In the period January to May 1972 three abortions were performed because of natural rubella infection in susceptible women in the first trimester of pregnancy.

\section{Discussion}

The submission of three fetal samples after termination of pregnancy within three months in 1972 as outlined above has given rise to local concern. If experience in Leicestershire is repeated elsewhere the number of terminations on grounds of substantial risk of the child being abnormal might be expected to rise significantly as rubella vaccination of women increases. Consequently it would be helpful from an epidemiological viewpoint if the Registrar General could make available the appropriate detailed statistics collected under schedule 2 of the Abortion Regulations 1968.

The risk of potential damage to the fetus from vaccination has been widely publicized to doctors. As there is an increasing use of nurses in immunization programmes there is a need to make similar information available to all nursing staff as well as the general public if domestic tragedies and litigation are to be averted. Since rubella vaccination in women is not recommended as a routine procedure it is advisable that the vaccine should be administered by doctors only, as is the case with smallpox vaccination (Department of Health and Social Security, 1970a).

Ideally seronegative women should be identified before pregnancy and offered protection. Had a prevaccination haemagglutination inhibition test been performed in four of the six cases reported probably in some if not all a positive titre would have proved rubella vaccination and the subsequent termination unnecessary. Unfortunately, the identification of the $15-20 \%$ of susceptible women (Public Health Laboratory Service, 1967) is an enormous problem, and the prevention of vaccination in early unrecognized pregnancy is difficult.

Of the three categories of potential vaccinees listed above, the group presenting least difficulty are women in the postpartum period, as the complication of pregnancy is minimal at this time. The risk cannot be ignored, as Sharman (1966) has claimed that one in six women ovulates within two months of delivery. Because of this MacDonald et al. (1971) recommended oral contraception for three months after vaccination in a trial in the Manchester region. In spite of these precautions two of the 153 women involved became pregnant, but spontaneously aborted. If this counsel is accepted it reinforces the need for rubella vaccination to be carried out by doctors, who would also be responsible for advice on contraception.

From a procedural point of view blood should be taken routinely during the antenatal period and examined for haemagglutinating inhibition antibodies. Susceptible women should be vaccinated within the first few days after delivery, with appropriate contraception for at least two months after vaccination. Routine testing for rubella antibody at antenatal clinics would help in time to evaluate the efficacy of the present recommended policy of vaccinating girls aged 10-13 years (Department of Health and Social Security, 1970b). Initially this could involve about 800,000 rubella antibody tests a year in England and Wales, reducing to less than 300,000 when only primigravidae are tested.

The other groups-that is, those who request protection and women at special risk-present greater procedural problems. Again it is indefensible to administer rubeila vaccine without first determining the state of immunity. About $80-85 \%$ of patients with a positive haemagglutination inhibition test can be reassured that vaccination is unnecessary. The remaining $15-20 \%$ of seronegative patients may be given vaccine after ensuring that they are not pregnant at the time of inoculation and that conception is prevented for at least two months after vaccination. In the latter advice lies the difficulty. Clearly the risks of pregnancy must be explained carefully to the patient. Since there is a possibility of a birth defect in about $3 \%$ of all pregnancies in any event, it is advisable to reinforce the advice by insisting on a written consent bearing an appropriate warning before giving the vaccine.

The method of contraception is of course the prerogative of the patient after advice from her doctor. If the method of choice is an oral preparation it should be prescribed for two months before vaccination and at least two months afterwards, because protection is not consistent in the first month. Similarly, vaccination of adolescent girls and unmarried women should be approached on the basis of a personal interview taking account of susceptibility and the risk of pregnancy.

The procedure outlined above will do much to prevent inadvertent vaccination during pregnancy. Nevertheless, undoubtedly rubella vaccination complicated by pregnancy will still happen from time to time, and the medical attendant will be faced then with the responsibility of advising the patient of the risks. Unfortunately the risks to the fetus from attenuated rubella virus are by no means clear. The letter of the Chief Medical Officer (1970) states that "it is not known whether vaccine virus does reach and can harm the fetus as wild rubella virus does in early pregnancy." Review of the world literature shows that there are no reported cases of rubella vaccine embryopathy. Recovery of vaccine-like virus from fetal tissues in cases of natural and therapeutic abortions after rubella vaccination has been reported in the United States (Vaheri et al., 1969; Witte, 1971). On the other hand, several workeri have failed to isolate the virus from fetal tissue. In a recent report (Report, 1971) on 141 women whose immune status was not known and who were given rubella vaccine during pregnancy, 77 underwent therapeutic abortion without isolation of virus from the products of conception. A further 20 known susceptible women were given rubella vaccine, and of the eight electing to continue their pregnancy seven had clinically normal infants at birth and the other had not reached full term. It should be remembered that some defects might not be apparent at birth, and follow-up is necessary for several years.

Hence the family practitioner's responsibility is to explain the known facts to the patient rather than automatically recommend termination. If therapeutic abortion is thought prudent while uncertainty exists concerning the threat to the fetus the products of conception should be examined for the presence of virus.

\section{Conclusion}

The possible hazards in the administration of rubella vaccine should be made clear to medical practitioners (particularly those concerned with antenatal care), nurses and midwives, women of childbearing years, and their husbands. National figures should be made available for abortions related to rubella vaccination separately from those due to natural rubella.

It has been shown that giving rubella vaccine soon after the beginning of menstruation or early in the postpartum period is no guarantee against conception occurring in the potentially dangerous period. Any women of childbearing age shown by a serological test to be susceptible to rubella should be offered vaccination and be told by her doctor of the possible danger as well as being advised on an effective contraceptive method for two months before and two months after vaccination. She should also be asked to sign a form of consent to rubella vaccination. In this way it is hoped that a number of unnecessary terminations of pregnancy will be prevented.

We wish to thank Dr. J. O'H. Tobin, of the Public Health Laboratory, Manchester, and Dr. J. E. Banatvala, of St. Thomas's Hospital, for their help and advice, and Dr. Brian Whowell for his helpful comments. 


\section{References}

Department of Health and Social Security (1970a). International Certificates of Vaccination against Smallpox and Cholera, Circular 14/70. Revised. London, D.H.S.S

Department of Health and Social Security (1970b). Vaccination against Rubella, Circular 11/70. London, D.H.S.S.

Department of Health and Social Security (1972). Vaccination against Rubella for Women of Childbearing Age. Circular 17/72. London, D.H.S.S

MacDonald, H., Thompson, K. M., and Tobin, J. O'H. (1971). Practitioner, 207, 57 .
Report (1971). Morbidity and Mortality 20 100; U.S. Center for Disease Control.

Public Health Laboratory Service Rubella Working Party (1967). British Medical Fournal, 111, 638.

Chief Medical Officer of the Department of Health and Social Security (1970). Rubella Prophylaxis, Circular 9/70. London, D.H.S.S.

Sharman, A. (1966). Reproductive Physiology of the Post-partum Period. 4th edn. Edinburgh, Livingstone.

Vaheri, A. et al. (1969). American fournal of Diseases of Children, 118, 243. Witte, J. J. (1971). Canadian Fournal of Public Health, 62, Monograph Suppl., p.42.

\section{MEDICAL MEMORANDA}

\section{Idiopathic Gangrene in African Adults}

\author{
R. D. BARR, A. D. ROY, J. R. M. MILLER
}

British Medical fournal, 1972, 4, 273-274

Idiopathic peripheral limb gangrene in African adults and children is a well-recognized clinical entity (Turpie et al., 1967), and little evidence of a cause has been found (Bhana and Baddeley, 1970). We have defined abnormalities in the blood coagulation and fibrinolytic enzyme systems in two such adult patients which may offer a possible explanation for the clinical manifestations of the disease.

\section{Present Series}

Venous samples were collected in $3.8 \%$ sodium citrate (blood: citrate 9:1) and centrifuged at $1,200 \mathrm{~g}$ for $10 \mathrm{~min}$ at $4^{\circ} \mathrm{C}$. Thereafter the supernatant plasma was removed and was either tested immediately or stored at $-20^{\circ} \mathrm{C}$ for further study. Samples for estimation of plasminogen were processed as far as neutralization of $\mathrm{pH}$ in the assay procedure and stored for subsequent bulk assay at $-20^{\circ} \mathrm{C}$. Samples for estimation of fibrinogen and factors $V$ and VIII were delivered in $1-\mathrm{ml}$ aliquots into plastic tubes, each containing $1 \mathrm{mg}$ aminocaproic acid and likewise stored at $-20^{\circ} \mathrm{C}$ for bulk assay. Platelet substitute and rabbit brain thromboplastin (Diagnostic Reagents Ltd.), thrombin (Leo), streptokinase (Kabi), and urokinase (HoffmanLa Roche) were used.

The method of recording euglobulin lysis times is given in the Appendix. All tests of the coagulation and fibrinolytic systems were performed in duplicate. The results are recorded in the Table. The normal results were obtained from 25 healthy African women aged 19-39 years examined by the same techniques in the same laboratory (Barr et al., 1972).

Case 1.-A 30-year-old M'luhya woman was admitted to the Kenyatta National Hospital on 11 February 1971 with a six-month history of intermittent claudication of increasing severity in both legs. Examination on admission showed incipient gangrene of the legs with no palpable lower limb pulses. Sinus rhythm was present and there was moderate hypertension (B.P. $150 / 110 \mathrm{~mm} \mathrm{Hg}$ ). Physical examination showed no other abnormality. Despite bilateral lumbar sympathectomy and bilateral femoral artery disobliteration, followed by systemic heparinization (intravenous heparin $1.500 \mathrm{U} / \mathrm{h}$ ), loss of viability of the lower limbs progressed. The patient died suddenly on

University of Nairobi, P.O. Box 30588, Nairobi, Kenya

R. D. BARR, M.B., M.R.C.P., Lecturer in Medicine

A. D. ROY, M.B., F.R.C.s., Professor of Surgery

Kenyatta National Hospital, P.O. Box 30024, Nairobi, Kenya

J. R. M. MILLER, M.B., F.R.c.s., Senior Consultant Surgeon
1 March while being prepared for amputation. Histological examination of a biopsy specimen of the femoral artery showed recent occlusive thrombus with no abnormality of the vessel wall. At necropsy there was extensive antemortem thrombus in the aorta, both common iliac arteries, and both iliac veins. There was no apparent intrinsic vessel wall disease. A large recent pulmonary embolus was found in the right lung.

Results of Tests on Coagulation and Fibrinolytic Systems

\begin{tabular}{|c|c|c|c|}
\hline Investigation & Case 1 & Case 2 & Normal Value \\
\hline 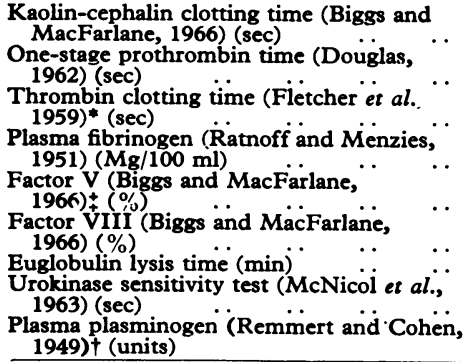 & $\begin{array}{c}26 \cdot 5 \\
17 \\
6 \\
530 \\
175 \\
189 \\
800 \\
340 \\
4 \cdot 7\end{array}$ & $\begin{array}{r}16 \\
5 \\
683 \\
195 \\
189 \\
1,440\end{array}$ & $\begin{array}{c}40 \pm 7.5 \\
16 \pm 2 \\
9.5 \pm 2.5 \\
295 \pm 95 \\
103 \pm 39 \\
96 \pm 32 \\
217 \pm 95 \\
282 \pm 92 \\
3.9 \pm 1.5\end{array}$ \\
\hline
\end{tabular}

* Method of Fletcher et al. (1959), with the modification that concentration of thrombin used was $25 \mathrm{U} / \mathrm{ml}$, compared with $10 \mathrm{U} / \mathrm{ml}$ in the original method.

† Method of Remmert and Cohen (1949) as modified by Alkjaersig (1960). $\$$ Method of Biggs and MacFarlane (1966), with the modification that concentra-
tion of calcium chloride used was $0.0125 \mathrm{M}$.

Case 2.-A 30-year-old Kikuyu woman was admitted to the Kenyatta National Hospital on 19 July 1971 with a history of rapidly progressive gangrene of both legs over a period of 17 days. During that time she had also become incontinent of urine. Examination on admission showed wet gangrene of both legs to the mid-tibial level, with palpable femoral and popliteal pulses. Sinus rhythm was present and she was normotensive. No other abnormality was found. While surgical toilet was being carried out under general anaesthesia on 9 August she died suddenly. At necropsy no definite cause of death was defined. There was bilateral pyonephrosis, with extensive thrombus in the major arteries of the legs in the absence of obvious disease of the vessel wall. The cerebral, coronary, and pulmonary circulations were normal. Histological examination of an arterial biopsy specimen taken from the site of surgical toilet showed recent occlusive thrombus with no abnormality of the vessel wall.

In neither patient was there a history of antecedent illness of any kind known to predispose the vascular disease.

\section{Comment}

Turpie et al. (1967) described the cases of three children who had idiopathic peripheral gangrene. All showed impaired fibrinolysis as a result of diminished levels of plasma activator and increased levels of inhibitor. The present patients, in addition to having the former abnormality, had raised levels of plasma fibrinogen, factor V, and factor VIII and 